\title{
Fertility Transition and Its Socioeconomic Impacts in China
}

\author{
Dr. Peng Xizhe, School of Social Development and Public Policy
}

Fudan University, Shanghai, China

Over the last half a century, China witnessed very rapid fertility transition. Its total fertility rate declined from around 6 in the 1960s down to below replacement level in the 1990s and has maintained at such a low level since then. The Chinese fertility transition is characterised by its rapidity and strong government intervention, and has profound Impacts on China's socioeconomic development.

\section{Past and current fertility in China}

Although large family used to be desired by Chinese culture, the natural fertility level in China was never as high as that recorded in the Hutterites population. According to historical studies, the TFR in the natural fertility regime was around 7-8 in Chinese society ${ }^{1}$. High fertility was balanced by high mortality, which resulted in slow and undulated population growth in Chinese history.

The 1950s and the 1960s witnessed very high fertility, except for the period of 1959 - 1961 when mismanagement and natural disaster caused massive excess mortality and very low fertility (Peng, Xizhe, 1987). China's nation-wide fertility transition started in the early 1970s, which was initialised by the government sponsored family planning programme. The national total fertility rate declined sharply from 5.8 in 1970 to 2.8 in 1979, a more than fifty per cent decrease. This is one of the rapidest fertility declines ever recorded in the world. While the government programme has played a crucial role in bringing down Chinese fertility, the fundamental changes that have taken place in China's socio-economic structure since 1950 have also undermined the century-long reproductive norms and paved the way to the fertility reduction.

\footnotetext{
${ }^{1}$ For example, see Zhongwei Zhao, 'Deliberate Birth Control Under a High-fertility Regime: Reproductive Behavior in China before 1970’, Population and Development Review, 23(4): 729-767
} 
It is often assumed that once fertility transition has started, the momentum would maintain and fertility will inevitably reach replacement level (Cleland \& Wilson, 1987). However, China's marked fertility reduction that had occurred in the 1970s did not get the same momentum into the 1980s, despite government efforts in implementing the much more rigid family planning regulation, the so-called "One-Child per family" programme. The potential for fertility decline created by the socio-economic changes of 1950-70s seems to be exhausted by the 1980s, leading to a TFR fluctuating between 2.32.9 .

Patterns of fertility transition in the 1980s indicate that China might have experienced two different kinds of fertility decline in these two decades. While the decline in the 1970s was mainly from very high to low fertility, the 1980s witnessed a decline from low to near or even below replacement-level fertility. The two kinds of fertility decline cannot be considered different only in the numerical sense. It seems that the early transition is relative easier and could proceed fast in a very short time period, but the later is much more difficult and requires somewhat more fundamental shift in socio-economic condition and the value system related to reproduction.

The early 1990s witnessed another nation-wide downward trend of fertility, with the coastal 'opened-up' areas at the fore. This new wave of fertility decline is certainly benefited from the economic reform and social changes generated from economic development. Moreover, the impact of the re-affirmed government commitment to population control should never be under-estimated. According to official statistics, the TFR was reduced from 2.3 in 1990 to 2.0 in 1992, and has remained below replacement level since then.

It has been a subject of controversy whether fertility in China was dropping as rapidly as indicated by the official statistics. Some demographers argue that the official birth statistics are subject to serious undercounting (Attane \& Sun 1999). The State Family Planning Commission may be the only government agency in China that openly admits the problems in its statistics and tries to correct them. The commission has conducted annual random survey to double check quality of population data and made great efforts to improve the accuracy of statistics. Results from these surveys varied widely between provinces and regions. In areas like Shanghai and Jiangsu, it was 
reported that more than 99 per cent of the births were registered, while underreporting could mount to more than 20 per cent in some other rural locations ${ }^{2}$.

It is interesting to note that the total fertility rates of the 1990s that were derived from several national surveys, both conducted by the State Statistics Bureau and the State Family Planning Commission, were consistently around 1.6, in spite of changes in sample selection and methods of field work ${ }^{3}$. These estimates to some extent are in contradiction to people's general impression on China's reality as 2 or 3 children per family is still a prevailed phenomenon in many rural areas. So far, there is no single estimation of TFR that is widely accepted by the scholars. However, the publicised official figure, say TFR around 1.7-1.8, in my opinion and also commonly cited by researchers, is not far away from the reality ${ }^{4}$.

Figure 1 about here

Big rural-urban gap in total fertility rate emerged firstly in the early 1960s when the compensational fertility surge was not occurred in the same magnitude in the urban area. In the cities, the contraceptive and other birth control services were available in the 1960s that led to the earlier fertility decline in China's urban area. The reproductive behaviour has continued to be differentiated between China's rural and urban population that could be mainly attributed to the factors linked to differential policy measures and socioeconomic settings. By now, while the one child per couple is a common practice in Chinese cities, two children per family is the general phenomenon in China's countryside.

There are always marked regional variations in fertility among China's provincial units, but the gap has been narrowing in the recent years. This phenomenon is clearly associated with the different path of fertility transition among China's provincial units. While big municipalities such as Shanghai and Beijing began their fertility decline as

\footnotetext{
${ }^{2}$ As these surveys were conducted in small scale, these data could not be used to represent the provincial features of birth reporting, or to infer to the national pattern.

${ }^{3}$ These surveys include 1992 Fertility Survey (Sample size of 380,000 ) conducted by the State Family Planning Commission, and 1995 1\% National Population Sample Survey, etc.

${ }^{4}$ It is unwise at present to discuss the issue of real fertility rate, as valid data sets are not adequately available. In a Chinese Government Directive issued in March 2000, it just simply indicates that China's fertility is below 'replacement level'. See also Yu Xuejun \& Xie Zhenming eds. China's Population Development Review, P. 41-43 , Beijing: People’s Publishing House, 2000.
} 
early as in the early 1960s, fertility transition only started in 1980s in some of the western provinces. Even with this regional variation, it seems clear that there has been a general trend of fertility convergence over time, which is evidenced by the decline of the fertility variance among provinces.

Figure 2 about here

Fertility level remains quite different between ethnic population groups. As birth control has long been vigorously implemented among the majority Han population, family planning programme has just started its formation for some minority nationalities (such as Tibet population). Among China's 55 minority groups, the fertility levels of Korea and Manchu women were very low, but were the highest among the Uygur and Kazak nationalities. The relative high fertility is one of the main causes that resulting in the increased share of China’s minority population among the total population.

\section{The role of government population policy and programme}

China's general population policy at present can be described as 'Controlling population quantity, improving the quality of life, and make efforts to solve aging problem'. The family planning programme is the core of China's national population programme, which is mainly managed by the State Population and Family Planning Commission with support from other government agencies and various NGOs such as China Family Planning Association and All-China Women's Federation etc.

The success of China's birth control has for a long time been heavily depended on government administrative intervention. The programme was initialised at the first instance by the central government and carried out through a top-down network. Since later 1980s, a target responsibility system has been established and functioned well since then. The system requires that heads of Party organisations and governments at all levels take the full responsibility for implementing population programme, through comprehensive management and co-operation between governmental departments and non-governmental organisations, and between different development policies and 
programmes. It aims to ensure the fulfilment of the population growth plan that is set up for each locality. Meanwhile, individual cadres' career development and position promotion would be closely affected by their achievements in family planning work.

The basic principles of the family planning programme are "to promote late marriage and deferred childbearing, to encourage people to have fewer but healthier births, to promote the practice of 'one child per couple' and to encourage a longer birth spacing for couples who have practical difficulties if they only have one child.” This policy took considerable time to develop and the intention for further improvement has never been given up, even though the Government repeats the confirmation of 'keeping the family planning policy stable' each year.

One of the salient features of China's family planning programme is its decentralised policy formation and operation. Under the general guidance from the central government, it is the local governments, primarily the provincial governments that are responsible for the formulating and implementation of the programme ${ }^{5}$. In other words, local authorities have been given some flexibility in adapting the national policy in order to accommodate the vast regional differentials in social, economic and cultural conditions. As a result, the current family planning regulations can be grouped into four major categories ${ }^{6}$. (Table 1 )

These varied policies are implemented in different localities. Based on population distribution in 2000, Guo and his colleagues claimed that the one-child, 1.5 child, 2 children and 3 children policies were implemented among 35.4\%, 53.6\%, 9.7\% and 1.3\% of China's population respectively ${ }^{7}$. In other words, if all Chinese couples follow local family planning regulations, the total cohort fertility rate in China should be 1.62 in $1990 \mathrm{~s}^{8}$. The figure declined to around 1.5 as more Chinese become urban residents.

\footnotetext{
${ }^{5}$ Actually, it is the local People's Congress, the Chinese Parliament, that with the authority in drafting local family planning regulations and making it to be implemented.

${ }^{6}$ Detailed discussion of the issue could be seen in Xie Zhenming, 'Population Policy and the Family Planning Programme', in Peng Xizhe and Guo Zhigang (eds.), The Changing Population of China, pp.5455, Oxford: Blackwell Publishers, 2000.

${ }^{7}$ Guo Zhigang et al, "Diversity of China‘s Fertility Policy by Policy Fertility” , Population Research , No.9, September, 2003 (in Chinese)

${ }^{8}$ This is refereed as the policy fertility, which is a weighted average assuming reproductive behaviours of all couples in different locations and of different nationalities following the local government family planning regulations. The figure was calculated by the State Family Planning Commission in early 1990s based on demographic structural pattern (rural-urban, Han-minority, etc.) that was prevailed at that time.
} 
Table 1: Comparison of Various Local Family Planning Regulations, 1990s

\begin{tabular}{|c|l|l|}
\hline Group & Major Policy Regulations & Coverage \\
\hline 1 & $\begin{array}{l}\text { One child with very few } \\
\text { exceptions in allowing couples to } \\
\text { have two children }\end{array}$ & $\begin{array}{l}\text { All urban residents and rural } \\
\text { couples in Jiangsu and part of } \\
\text { Sichuan province }\end{array}$ \\
\hline 2 & $\begin{array}{l}\text { Two children if the first one is a } \\
\text { girl (1.5 child policy) }\end{array}$ & $\begin{array}{l}\text { Most rural couples in } \\
\text { provinces }\end{array}$ \\
\hline 3 & $\begin{array}{l}\text { Two children with a four-year } \\
\text { spacing } \\
\text { Two or three children }\end{array}$ & $\begin{array}{l}\text { Farmers in 5 provinces and } \\
\text { autonomous regions } \\
\text { Minorities in the rural areas of } \\
\text { minority autonomous regions } \\
\text { Rural Tibetan population }\end{array}$ \\
\hline 5 & No numerical regulation & \multicolumn{2}{|c|}{} \\
\hline
\end{tabular}

Sources: Details of provincial family planning regulations are available at www.cpirc.org.cn (accessed 15 Aug. 2002).

The complex policy reflects the greatly varied economic and social realities in different Chinese regions. Furthermore, the differential local policy is a compromise between the central guidance on population control and the local situation, both in terms of socio-economic development and the political commitment of the local government. Chinese farmer families can have two children in general, which is rationalized by the factors that farmer families depending on strong labour for agricultural production and family support (primarily support by married son (s)) for older age security as there is almost no well-covered government sponsored pension system operating for Chinese farmers. The success of the programme relies on local government commitment, local socioeconomic conditions, persistence of local traditional culture, etc.

Financial incentive and disincentive measures have been widely used in the programme. Since 1991, the political commitment to population control has been reaffirmed and the mass is widely mobilised once again ${ }^{9}$. As a positive result of these commitments, financial input for family planning has increased steadily. More personnel

\footnotetext{
${ }^{9}$ Such as the fully implementation of family planning responsibility system, the start of the annual conference on population and family planning work which is held during the time of the annual national People’s Congress in March, and participated by all central and provincial top leaders.
} 
have been recruited and trained to work in the family planning programme. The quality of birth control service has to some extent been improved. Moreover, the government requires that relevant social and economic policies should be in compliance with the population policy. These measures work effectively in terms of public awareness and the implementation of population programmes, and play an important role in further fertility decline in the 1990s.

Along with the strong government commitment, the programme has now put more emphases on people's volunteer participation. Couples are expected to, under the general guidance of government population policies, make autonomous decisions regarding the methods of contraception, birth interval and other reproductive health matters. Efforts have been made to promote education and information dissemination, and on provision of better, continuous and regular contraceptive service. Moreover, family planning programme has extended to other fields relevant to people's daily life in order to attract wide voluntary participation. Various experimental projects relating family programme with women's empowerment and community development have also been carried out. Many of them are supported by international organisations such as Ford Foundation. In more recent years, more attention has been paid to the provision of social welfare to rural elderly who following up the government family planning regulation in the past.

There are shortcomings as other mass programmes. China's family planning programme is heavily reliant on female contraceptive methods ${ }^{10}$. The local family planning policies to some extent institutionalise the traditional patriarchal ideas and son preference as many provinces allowing rural couples have two children if the first child is a daughter. The programme has been promoted for a long time with little strong support from other socio-economic institutions, so that it has been mainly implemented through government administrative network. The programme requires couples to reduce the number of children they produce, but is unable by it itself to provide adequate social support for people to adjust their strategy for family formation and necessary compensation for couples to alleviate life risks in the context of low fertility. The later task is certainly beyond the capacity of the family planning programme. Punitive

\footnotetext{
${ }^{10}$ According to government statistics, male methods accounted for only 14.7 and 13.1 pert cent of total contraception in 1994 and 1999 respectively.
} 
packages, in some cases became coercive measures, were widely used particularly in the 1980s by local cadres although the government emphasis on Mass Line and against coercion in general. Levying fines become one of the causes of social tension between cadres and the public especially in the rural areas. The relationship between societal interests and individual rights is also an area that was neglected to some extent.

\section{Factors that affecting regional variations in fertility}

As discussed in the previous section, the government commitment and population programme are major determinants of China's rapid fertility decline. However, given the characteristics of China's fertility transition, two other factors, the socio-economic development, and reproductive culture, must be taken into consideration in any analysis of past and future fertility trend in China. China's fertility transition is a process of diffusion: it started from some developed regions and urban centres, and then diffused to other parts of China. There are always marked regional variations in fertility patterns, both in terms of the absolute level and the path of change.

Based on our understanding of the fertility transition, relevant socio-economic indicators are chosen and conventional statistic analysis is carried out. As China's marked fertility transition occurred mainly in the three decades of 1970s, 1980s and 1990s, our analysis uses data of these periods ${ }^{11}$. Results from table 2 reveal that the general relationships between fertility level and selected socio-economic variables are maintained. It means that general development level is negatively correlated to the fertility level. Figure 3 is just an example of such close relations.

Figure 3 about here

Nevertheless, the relative importance of various socio-economic factors on fertility has changed over time. On the whole, the government population policy and programme (indicated by Policy TFR) and general level of socio-economic development (represented by Per Capita GDP and Consumption, and Proportion of Urban Population etc.) are the most crucial determinants of China’s regional fertility variation. (Table 2)

\footnotetext{
${ }^{11}$ Data set in Table 4.
} 
Table 2. Correlation Coefficients between TFR and selected socio-economic variables

\begin{tabular}{|l|c|c|c|}
\hline Variables & $1980 \mathrm{~s}$ & 1995 & $1997-99$ \\
\hline Per Capita GDP & -0.61 & -0.74 & -0.601 \\
\hline Proportion of Urban Population & -0.57 & -0.71 & -0.513 \\
\hline Per Capita Consumption & -0.55 & -0.69 & -0.569 \\
\hline Policy TFR & 0.76 & 0.69 & 0.792 \\
\hline Female late Marriage Rate & -0.55 & -0.19 & -0.193 \\
\hline Female Contraceptive Prevalence & -0.81 & -0.23 & -0.334 \\
\hline Female Illiterate Rate & 0.56 & 0.60 & 0.713 \\
\hline
\end{tabular}

Sources: see table 4.

Table 3. Determinants of China’s fertility level by multiple linear regression

\begin{tabular}{|l|l|c|}
\hline \multirow{2}{*}{ Independent Variables } & \multicolumn{2}{|l|}{ Dependent Variable TFR } \\
\cline { 2 - 3 } & $1980 \mathrm{~s}$ & $1990 \mathrm{~s}$ \\
\hline Constant & 8.992 & 0.542 \\
\hline Per Capita GDP & 0.289 & -1.045 \\
\hline Per Capita Consumption & -0.916 & 0.721 \\
\hline Proportion of Urban Population & 0.171 & -0.325 \\
\hline Policy TFR & -0.120 & 0.420 \\
\hline Female Contraceptive Prevalence & -0.832 & 0.056 \\
\hline Female late Marriage Rate & 0.066 & 0.067 \\
\hline Female Illiterate Rate & 0.051 & -0.042 \\
\hline $\mathrm{R}^{2}$ & 0.877 & 0.775 \\
\hline F & 21.482 & 10.844 \\
\hline
\end{tabular}

Note: All regression coefficients are standard $\beta$ values.

It could be seen from table 3 that the values of $\mathrm{R}$ squared for both 1980s and the 1990s are very high, which indicates a good fit of the regression model. However, there are different signs of many variables between 1980s and the 1990s in the regressions, which may cause confusion. In order to assess the relative importance of independent 
variables, step-wise regression method is employed, which results in a simplified regression model for the 1990s:

$$
\begin{aligned}
& \mathrm{Y}=1.097+0.921 \mathrm{X}_{1}-0.017 \mathrm{X}_{2} \\
& \mathrm{R}^{2}=0.722, \mathrm{~F}=35.109, \beta \mathrm{X}_{1}=0.486, \beta \mathrm{X}_{2}=-0.538 \\
& \mathrm{Y}: \text { TFR } \\
& \mathrm{X}_{1} \text { : Policy TFR, } \mathrm{X}_{2} \text { : Proportion of Urban Population }
\end{aligned}
$$

The two variables used in the equation are policy TFR and the proportion of urban population. They could explain 72.2 per cent of regional fertility variations. Compared to the result from table 3, the remaining 5 variables only add 5 percentages more to the model. The variable of policy TFR reflects both the government commitment on population control and the population composition, ethnic and rural-urban, the above analysis shows that there is a strong association between fertility and the proportion of urban and minority populations at the aggregated level, provinces with a high proportion of urban population and a low proportion of minority population have achieved low fertility. It reflects the fact that deliberate fertility control was first adopted by the Han population and started in urban and coastal areas, then gradually adopted by other minority populations and diffused to rural and inland areas. It also reflects differences in the family planning policy and its implementation between Han and minority populations and between urban and rural areas. However, we should also note the considerable heterogeneity in urbanisation and population's ethnic composition among provinces with a similar fertility.

\section{Socioeconomic impact of fertility transition}

At the launch of the so-called "One-Child-Policy", the intention was made clear that this should be a policy measure for a period of only 20 to 30 years 12 . After more than 20 years of implementation, it has met its primary objective to slow down China's population growth. It estimates China could now have 400 million more people if no family planning programme was carried out. On the other hand, there are also profound

\footnotetext{
${ }^{12}$ See Guanyu kongzhi woguo renkou zengzhang wenti zhi quanti gongchan dangyuan, gongqing tuanyuan de gongkaixin (An Open Letter to All Members of the Communist Party and Communist Youth League), Central Committee of Chinese Communist Party, 25 Sep. 1980.
} 
socio-economic and demographic consequences. Current policy debates have concentrated on these issues.

In 2000, there were 88.11 million elderly (people over 65 years), and the proportion in the total population for the first time in China's history exceeded 7 per cent, indicating that for the country as a whole, China had become an "aged society”.13 The total elderly population (aged 65+) increased up to 100.45 million in 2005, occupied $7.69 \%$ of the overall population, an increment of 13.58 million over this five-year period. The number is expected to increase by 3 times over the first half of the 21st century.

An aging population has long been a major challenge facing many cities and the wealthier rural areas in the eastern region. In Shanghai, 13 per cent of the city population is 65 and above. On the other hand, Qinghai province is projected to enter the aging society stage in as late as 2014 . Regional variations in population aging are very similar to the regional variations in current fertility, indicating that the aging process is mainly caused by the pattern of fertility decline.

China may be the first major country to grow old before it grows rich. By the middle 2005, China's urban pension system only covered a total population of 168.68 million, including about 42 million pensioners and 125 million employees who contribute to the pension fund. Only 30 per cent of all urban residents, or 15 per cent of employees, were covered by the program, far less than the world average.

The soaring number of senior citizens has put a severe strain on China's social security, medical care and the social service sector. On the whole, the Chinese pension system is still a pay-as-you-go system albeit the introduction of a partly funded multipillar system in the 1990s. The current system is burdened by unfunded liabilities from the old system that is called Legacy Debt. The total annual net input from China's Government revenue into pension fund to balance the system amounted to 52.4 billion Yuan in 2004, and accumulated input reached 170 billion between 1998 and 2005. There is a total deficit of 2.5 trillion Yuan in China's urban pension system. The estimated ratio of implicit pension debt (IPD) to national GDP would range from 80.8 percent to 145.4 per cent, based on different assumptions of the discount rate used in the simulation.

\footnotetext{
${ }^{13}$ National Bureau of Statistics of the People's Republic of China, Communiqué on Major Figures of the 2000 Population Census, no. 1, 28 Mar. 2001.
} 
The aging issue is much more complicated in China's countryside. There is very limited social welfare provision to rural elderly, such as five-guarantee system and poverty relief subsidies. On the whole, the elderly farmers in China are still depending on their families, particularly their sons to provide old age support both in terms of finance and service provision. Furthermore, large scale rural-urban migration, indicated by millions of young people moving out, has worsened the aging process in China's rural area.

An abnormal sex ratio at birth is another issue linked to China's fertility transition. Researchers in the late 1980s attributed the situation mainly to misreporting of births ${ }^{14}$. However, it soon became clear that it was real and that pre-birth selective abortion in favour of boys was the primary cause ${ }^{15}$. The continuous and increasing skew in the sex ratio at birth indicates that the situation has worsened over the years ${ }^{16}$. It was 108.5 in 1982 and 110.9 in 1987. It was reported that in 2005 for every 100 new-born girls, there were 124 boys, compared to 119.92 in 2000 and 111.42 in $1990^{17}$.

Some blamed the rigid implementation of the family planning programme as the major cause. Indeed, there is some kind of relationship between the fertility level and abnormality of sex ratio at birth. Provinces with a normal or slightly higher sex ratio at birth actually belong to two groups. One is where there is a concentration of minority people and the fertility rate is relatively higher, the other group is where there is low fertility. The most serious problem is occurring in the provinces/regions which fall somewhere in between. However, similar abnormality can also be found in South Korea and India with very different family planning programmes. ${ }^{18}$

\footnotetext{
${ }^{14}$ For example, Zeng Yi, et al., "Causes and Implications of the Recent Increase in the Reported Sex Ratio at Birth in China," Population and Development Review 19, no.2 (1993): 283-302.

${ }^{15}$ According to the 2000 Population Census, the sex ratio for the 0-4 and 5-9 age groups is 119.5 and 114.4, respectively. If misreporting caused the abnormal sex ratio at birth, it would re-appear in the corresponding age groups in the census or surveys conducted a few years later. The consistence between these surveys and censuses is a good indicator of the real abnormality of the sex ratio at birth.

${ }^{16}$ Regulations, including heavy penalties, have been set up in many provinces/regions to prevent medical doctors from using ultrasound machines to identify the sex of the foetus. See for example, http://sdrd.sdchina.com/zfjd/400012 (accessed 23 Nov. 2002).

${ }^{17}$ Report from China’s State Family Planning Commission. See http://www.sfpc.gov.cn/cn/news200205161.htm (accessed 2 Nov. 2002).

${ }^{18}$ See for example, Chai Bin Park and Nam-Hoon Cho, "Consequences of Son Preference in a Low-fertility Society: Imbalance of Sex Ratio at Birth in Korea,” Population and Development Review 21, no. 1 (1995): 59-84.
} 
The issue is deep rooted in Chinese traditional culture and the currently socioeconomic development level as well. Son preference has its rational especially with old age security in China's countryside. The government has applied rigid policy measures to fight with the problem, including serious crackdown on illegal sex identification. Sex identification of the fetus or sex-selective pregnancy termination for non-medical purpose is strictly forbidden and medical personnel involved in this wrong conduct will be seriously penalized. Programmes such as "care for girls project", "Happiness Project" and the "Spring-bud Programme" have been carried out to promote the gender equality. The government's target is to balance the currently unbalanced sex ratio in 2010. It is not an easy job.

A marriage squeeze is expected that was revealed by a thorough study on China's population development strategy. It is estimated that there will be 30 million more males than women in the age groups of $25-40$ by the year of 2025 . The Chinese society has to cope with the problem seriously regardless the cause of the problem.

There are other consequences caused by or closely linked to China's population programme. The different paths of fertility transition have resulted to the varied regional patterns of labour force supply, which is on of the major causes of large-scale labour migration from rural to urban, and from inland provinces to costal regions. By the early $21^{\text {st }}$ century, the cohort of 'Single Child' has amounted to more than 100 million. This cohort has many unique characteristics that will have profound effects on China's future socioeconomic development, societal and family structure, and even political reform.

\section{The future perspectives}

In March 2000, Chinese government issued a directive to reaffirm its commitment to population control ${ }^{19}$. Seven years later, a new document (will be called the Document in the following discussion) has been published calling for the continuous efforts in China's

\footnotetext{
19 “Decision on Strengthening Population and Family Planning Work, Maintaining low Fertility”(中共中央 国务院关于加强人口与计划生育工作稳定低生育水平的决定), Directive issued by CCCP and the State Council, $2^{\text {nd }}$ March 2000.
} 
population struggle $\mathrm{e}^{20}$. Stabilizing the low fertility level is viewed as a primary task for population and family planning programme in the new era, and the 11th Five-Year Plan Period is regarded as the critical time for fulfilling this task. It seems certain that the Chinese government will maintain its commitment to population control, and will make every effort to achieve its population target in the 21st century. The Document pledged to keep the nation's population under 1.36 billion by 2010 and under 1.45 billion by 2020 . The population annual increase rate in China is expected to maintain at a low level, but the absolute number of the increase will stand at 8 to 10 million people every year for the next 20 or more years.

There are concerns about the resilience of China's fertility transition and the possibility of fertility rebound if the government, either voluntarily or forced to, loses control on population issues. On the other hand, scholars in favour of relaxation of the current population policy warn that once low fertility becomes social norm, it may not be possible to reverse the trend no matter what pro-birth policy measures are taken that is the experience of Singapore and Japan. The publication of the Document indicates that the present population policy will more or less maintain in effects for the coming years, allowing some minor modifications.

Given China's current socio-political settings, the government population policy will decide the basic level of China's fertility for the coming years. The deviation from this line will be determined jointly by the government's capacity in enforcing its population policy and programme, the societal change caused by China's social, economic and political reform, and people's general desire for family size.

The transformation of government organisations and functions is under way. The basic idea is to make the government focusing on certain important issues and the society will take care of the remaining things, or so-called 'small government and big social services' in Chinese. The government system is undergoing a profound restructure.

20 "Decision of the Central Committee of the Communist Party of China and the State Council on Fully Enhancing Population and Family Planning Programme and Comprehensively Addressing Population Issues” , 17 January, 2007, http://www.npfpc.gov.cn/en/en2007-01/news20070124.htm 
China's Population and Family Planning Law that came into effect as of September 2002 legalises the position of the family planning programme and its network in China. The programme, however, is facing more challenges than ever before.

Family planning is first and foremost a rural issue in China . Even after more than 30-years' rural reform, an extra child means not only an extra helping hand to rural household in sharing the agricultural workload in the field and raising farm productivity, but also an extra caregiver and provider for the parents in old age. To promote the family planning policy in rural areas, a subsidised pension programme to reward parents with only one child or two girls, has been implemented since 2004. The system provides a pension-like subsidy of no less than 600 RMB Yuan (\$75) each year to rural parents aged 60 and older who have only one child, or have two daughters. More than 1.35 million aged rural parents have already benefited from the subsidy programme which has been trialled in more than 10 provinces since 2004, and is going to extend to the whole country in the coming years. This is also an incentive for younger parents to exercise birth control. At present, the annual cost of the subsidy programme is about 1.2 billion RMB Yuan. This programme is one of the initiatives to establish a comprehensive social security system for millions of Chinese farmers. The sustainability of the programme needs to be tested by time.

The population issue is an important component of the government's functions of public management and social services. The Document required that fiscal input into population and family planning programmes should increase at a rate greater than the increase of current fiscal revenues, so as to guarantee the fund availability for implementation of family planning programme and other social support and preferential measures. Hence, per capita annual fiscal input into population and family planning programme at all levels shall reach RMB 30 Yuan per capita ${ }^{21}$.

Efforts have been made aiming to strengthen and improve development of a grassroots-focused Reproductive-health and family planning service delivery system. However, it is reported that in some local areas, the family planning offices, especially its technical unit, is transferred to be non-government institutions and financially

\footnotetext{
${ }^{21}$ The Document, 17 January, 2007, http://www.npfpc.gov.cn/en/en2007-01/news20070124.htm
} 
independent with partial government subsidies. Other reforms in China's public health and medi-care system may also affect the function and efficiency of the present family planning network as village clinics and urban community health centres are given more responsibility to deliver reproductive-health service. This change may not directly influences the quality of contraceptive service, but may make it more difficult now to keep people working for family planning programmes as job security reduces. Together with other administrative restructure, this may affect the capacity of the government in carrying out family planning since it has been largely depended on effective administrative system.

There should be no technical difficult for China's to reach its population target. Research and production of contraceptive devices have always been put at a very favourable position. The deepened involvement of China into globalisation of world economy may further facilitate the introduction of new and more effective birth control methods. If the political stabilisation and current path of development in China are maintained, it is quite possible for China to maintain a TFR around 1.7-1.8 in the coming years.

Meanwhile, people's volunteer participation and free determination will play much more important roles in determine the future fertility level in China. Fundamental changes have occurred in China's society and economy since the opening and reform. The same is true in people's reproductive behaviour. China's family planning programme has been supported in large by the public, particularly from the younger generations. The young generation has been growing up in a drastically changed environment. Their views on marriage, childbearing, and family are markedly differentiated from the traditional one. Small family norm has been widely accepted by the public, especially in those advanced regions and among the young generation. While there have always been gaps between the targets of the programme and public acceptance, the gaps reduced with the time passing. The society interests remain as the major rational for China's population policy and programme, but individual's rights get more attention. Population should be treated in a more comprehensive manner. Neither too high nor a too low fertility level is conductive to the sustained and coordinated process of China's modernization. It is the author's opinion that government intervention on reproduction will be gradually weakened along 
with China's further development and 'Two Children Family' will be a universally practised family norm in China in the 21st Century.

\section{Main Reference:}

Attane, I \& Sun Minglei (1999), 'Birth Rates and fertility in China: How Credible are Recent Data?’, Population: An English Selection, 11,pp.251-260

Banister, Judith, (1992), 'Implications and Quality of China's 1990 Census Data', paper presented at the International Seminar on China's 1990 Population Census, 19-23 Oct. 1992, Beijing.

Chen Wei, 'China's Low fertility (zhongguo de dishengyulu)', in the Special Issue of Population Research (renkou yanjiu) 1995.

Cleland. J. and C. Wilson, (1987), 'Demand Theories of the Fertility Transition: an Iconoclastic View’, Population Studies, 41,1

Department of Policies, Laws and Regulations of the State Family Planning Commission (DPLR), (1992), 'A Summary of the Family Planning Regulations in the 28 Administrative Units at the Provincial Level of the Country', China Population Sciences (in Chinese), No. 4, July 1992, also see China Population Today, Vol. 9, No. 5.

Gu Baochang \& Yang Shuzhang, (1991), 'Fertility Trends in Rural China in the 1980s: Cohort Effect Versus Period Effect', Asia-Pacific Population Journal, Vol. 6, No. 4, pp. 334.

Leete, Richard, (1991), 'Fertility Trends and Prospects in East and Southeast Asian Countries and Implications for Policies and Programmes', Population Research Leads, 1991.

Peng Xizhe, (1987) "Demographic Consequences of the Great Leap Forward in China's Provinces”, Population and Development Review, 13, 4, pp.639-70

--- (1993), "Regional Differentials in China’s Fertility Transition”, in Leete, R. \& I. Alam (eds.), The Revolution in Asian Fertility, Oxford: Clarendon Press,

Peng Xizhe and Guo Zhigang (eds.), The Changing Population of China, Oxford: Blackwell Publishers, 2000.

Zeng Yi, (1995), 'Has China’s Fertility in 1991 and 1992 been far Below the Replacement Level?', Population Research, May Issue.

--- (2000), 'Marriage patterns in Contemporary China', in Peng \& Guo (eds.), The Changing Population of China. Oxford: The Blackwell Publishers. Pp.91-100. 
Table 4: TFR and other major socio-economic indicators for China's provinces in the $1990 \mathrm{~s}$

\begin{tabular}{|c|c|c|c|c|c|c|c|c|}
\hline Provinc & 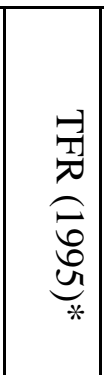 & 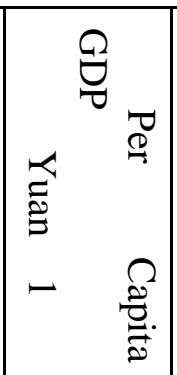 & 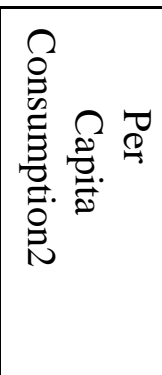 & 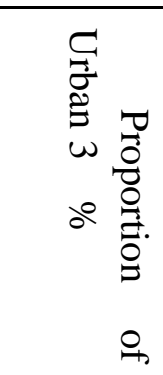 & 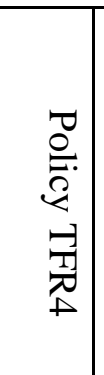 & 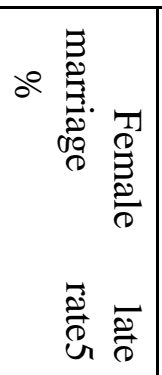 & 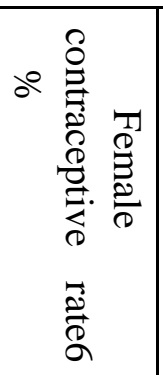 & 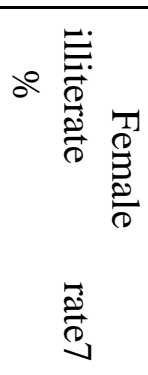 \\
\hline Beijing & 1.00 & 12740.18 & ${ }_{1} 3380.9$ & 63.74 & 1.33 & 84.51 & 90.08 & 11.18 \\
\hline Tianjin & 1.64 & 13256.40 & $4^{4515.4}$ & 56.54 & 1.35 & 62.76 & 91.66 & 16.19 \\
\hline Hebei & 2.19 & 5286.36 & 3 & 16.04 & 1.67 & 51.76 & 92.12 & 22.13 \\
\hline Shanxi & 2.15 & 4182.33 & $9 \begin{array}{l}1673.9 \\
9\end{array}$ & 23.36 & 1.69 & 64.45 & 90.25 & 14.33 \\
\hline $\begin{array}{c}\text { Inner } \\
\text { Mogolia }\end{array}$ & 1.97 & 4204.37 & ${ }_{1} 1851.5$ & 31.86 & 1.80 & 72.45 & 91.89 & 23.60 \\
\hline Liaoning & 1.69 & 7753.83 & $6^{3133.1}$ & 43.61 & 1.50 & 61.55 & 91.41 & 12.61 \\
\hline Jiling & 1.85 & 5000.48 & $4^{2543.8}$ & 40.94 & 1.50 & 49.09 & 73.21 & 13.80 \\
\hline $\begin{array}{l}\text { Heilongjian } \\
\text { g }\end{array}$ & 1.88 & 6350.31 & 5 & 43.81 & 1.44 & 48.88 & 93.12 & 15.50 \\
\hline Shanghai & 0.99 & 21162.14 & \begin{tabular}{|l} 
\\
1
\end{tabular} & 69.37 & 1.28 & 62.43 & 92.45 & 15.39 \\
\hline Jiangsu & 1.89 & 8410.36 & $9^{2922.2}$ & 23.40 & 1.52 & 70.59 & 93.60 & 27.62 \\
\hline Zhejiang & 1.61 & 9439.68 & $9^{3186.0}$ & 17.67 & 1.54 & 73.72 & 92.24 & 25.07 \\
\hline Anhui & 2.25 & 3841.93 & $8 \begin{array}{l}1932.0 \\
8\end{array}$ & 16.66 & 1.61 & 67.70 & 90.27 & 29.67 \\
\hline Fujian & 2.26 & 8212.25 & $2^{3336.4}$ & 18.00 & 1.61 & 49.73 & 91.25 & 32.94 \\
\hline Jiangxi & 2.41 & 3634.64 & $6 \quad 1681.6$ & 19.97 & 1.52 & 29.57 & 92.94 & 24.39 \\
\hline Shandong & 2.01 & 6719.48 & \begin{tabular}{|l}
2309.8 \\
1
\end{tabular} & 22.43 & 1.55 & 99.05 & 92.22 & 32.81 \\
\hline Henan & 2.74 & 3924.30 & $4^{1548.4}$ & 14.80 & 1.56 & 67.00 & 90.12 & 23.55 \\
\hline Hubei & 2.29 & 5085.01 & $5^{2210.2}$ & 24.47 & 1.55 & 49.32 & 92.85 & 25.46 \\
\hline Hunan & 2.16 & 4129.64 & \begin{tabular}{|l|}
2035.9 \\
\end{tabular} & 16.81 & 1.64 & 41.71 & 93.57 & 21.24 \\
\hline
\end{tabular}




\begin{tabular}{|c|c|c|c|c|c|c|c|c|}
\hline & & & 3 & & & & & \\
\hline Guangdon & 2.34 & 9433.48 & $7^{4082.3}$ & 27.50 & 1.85 & 71.59 & 85.44 & 22.09 \\
\hline Guangxi & 2.72 & 3666.72 & $5^{1833.3}$ & 15.31 & 1.57 & 61.52 & 90.09 & 21.35 \\
\hline Hainan & 2.67 & 5395.65 & 3 & 22.65 & 1.97 & 66.94 & 84.79 & 27.39 \\
\hline Sichuan & 1.85 & 3584.76 & $7_{7}^{1764.9}$ & 16.06 & 1.57 & 34.36 & 91.23 & 26.25 \\
\hline Guizhou & 2.85 & 1960.72 & $5_{5} 1283.1$ & 12.98 & 1.74 & 52.46 & 92.58 & 45.00 \\
\hline Yunnan & 2.61 & 3542.63 & 9 & 13.15 & 2.13 & 42.89 & 84.08 & 39.68 \\
\hline Xizang & 3.48 & 2332.50 & $88^{1172.0}$ & 13.73 & - & - & - & 68.98 \\
\hline Shannxi & 2.57 & 3233.22 & $4^{1557.2}$ & 19.84 & 1.64 & 57.28 & 90.73 & 28.84 \\
\hline Gansu & 2.05 & 2781.93 & $2^{1343.9}$ & 17.16 & 1.58 & 47.08 & 88.22 & 44.52 \\
\hline Qinghai & 2.37 & 3638.22 & $0^{1714.2}$ & 28.16 & 2.08 & 53.67 & 84.99 & 55.04 \\
\hline Ningxia & 2.53 & 3604.47 & $8{ }^{1674.6}$ & 25.39 & 2.06 & 45.50 & 90.26 & 34.17 \\
\hline Xinjiang & $2^{2.9}$ & 5309.63 & 2351.10 & 34.02 & 2.40 & 82.44 & 80.77 & 17.47 \\
\hline China & $\begin{array}{l}2.2 \\
0\end{array}$ & 6066.64 & 2427.51 & 26.98 & 1.62 & 58.85 & 90.40 & 25.54 \\
\hline
\end{tabular}

Note: Per Capita GDP refers to Average value of 1994-1998, compatible prices.

Per Capita Consumption refers to Average of 1995, 1997 and 1998, 1995 price.

Proportion of Urban refers to the average of 1991-1994 and 1997

Policy TFR refers to the weighted average of people covered by different family planning regulations in the later 1980s, which remained more or less unchanged in the 1990s.

Female late marriage refers to 1995

Female contraceptive rate refers to the average of 1990, 1993 and 1995

Female illiterate rate refers to 1996

Sources:

1. China Statistics Yearbook, 1985-1999

2. China Population Statistics Yearbook 1988-1998

3. China Family Planning Yearbook 1986-1996

4. Fertility data cited from Chen Wei, 'China's Low fertility', in the Special Issue of Population Research (renkou yanjiu) 1995. 
Figure 1. Fertility Trend in China, 1950-2000

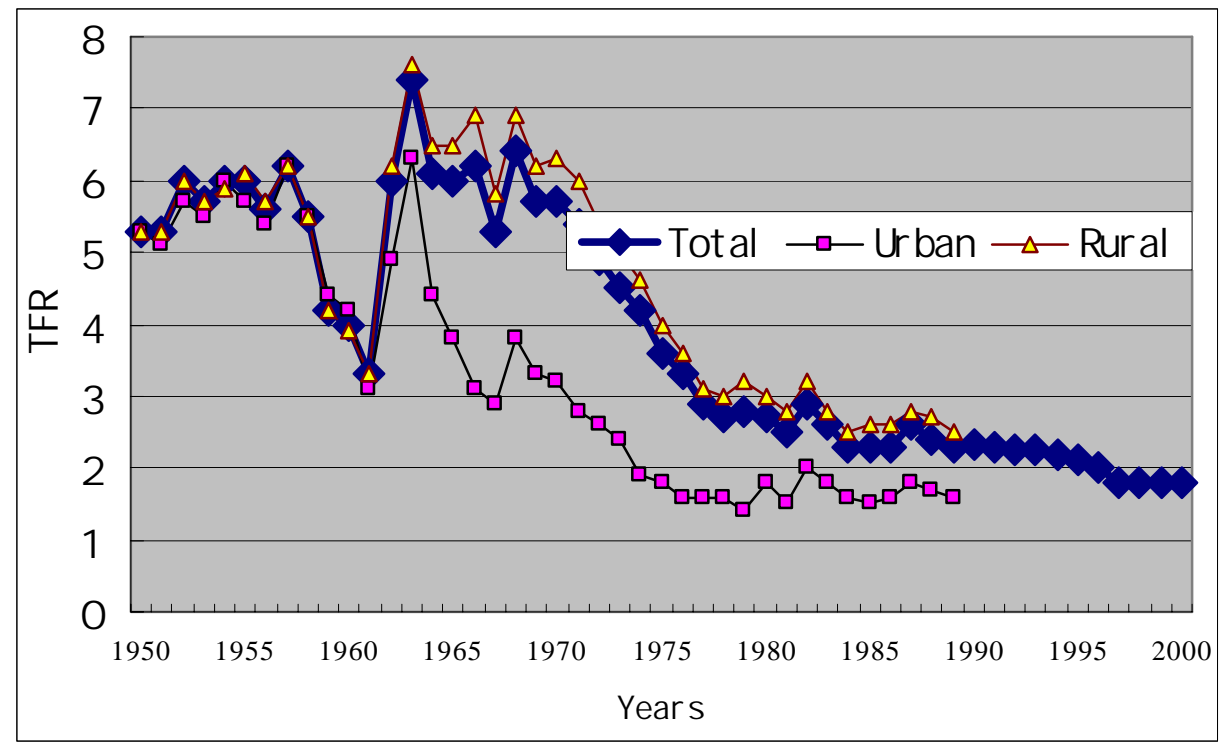

Figure 2 Provincial Fertility Pattern in China, 1997-1999

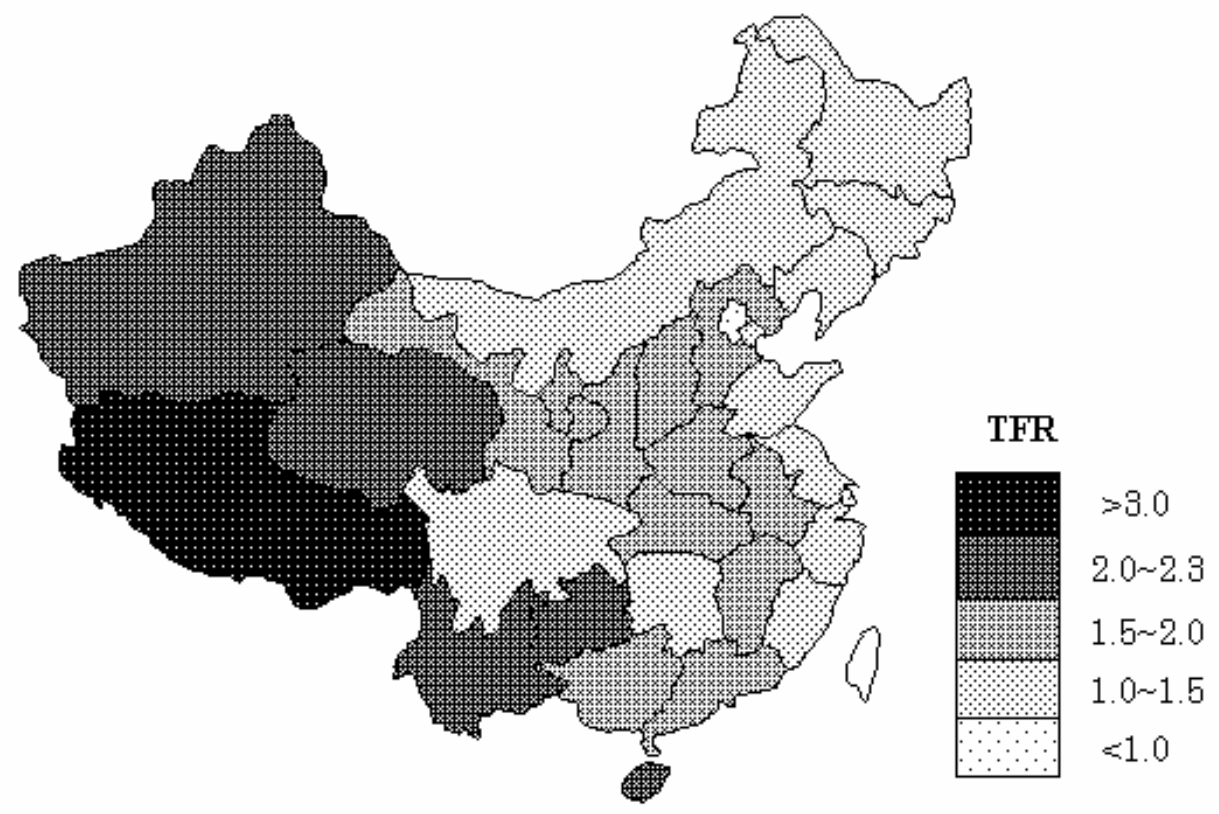

Note: Based on estimation by China's State Family Planning Commission. Data for Tawan, Hongkong and Macao are not included. 


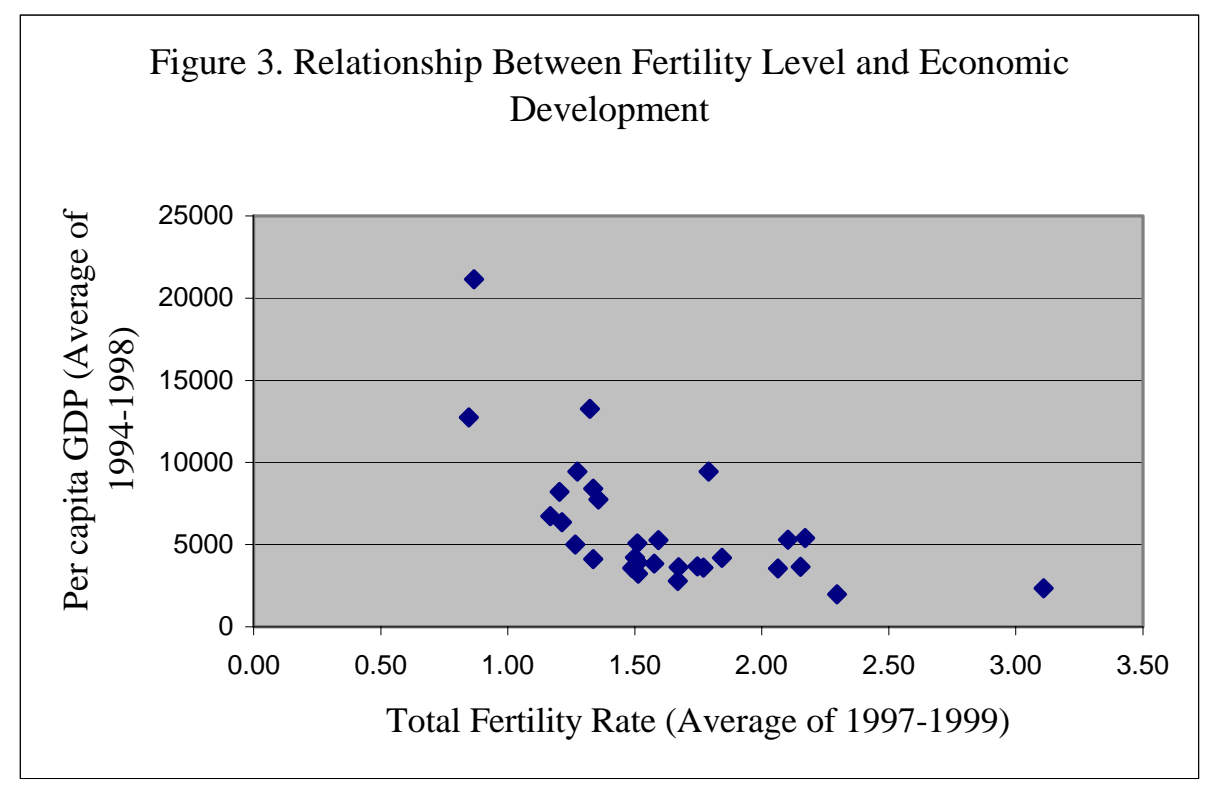

